\title{
Religion as an Influential Factor in Corporate Governance Structures
}

\author{
Paul Diaconu, Dan Dumitrescu \\ Bucharest Academy of Economic Studies, Bucharest, Romania
}

\begin{abstract}
Although the current economic crisis seems far from being over, economist's preliminary conclusion is that it has been triggered by the lack of morality of large financial institutions in developed countries that have infested the world public finance with toxic financial products. This lack of morality of the business environment seems to be a consequence of the suboptimal action of large financial companies that have put their short-term business interest above the general interests of the society they were part of, triggering the current world economic situation. The present article seeks to assess if perhaps religion, as the most effective means of imposing social morality has had an impact on the corporate governance decisions of corporations in countries with different religions. To this end, we have used the macroeconomic indicator GDP and its growth rate as a measure of corporations' managerial policies collective action. Those policies are/can be more or less influenced by the major religious precepts in the society where they act. Using these relationships we have attempted to give an assessment of the religious phenomenon impact (as an element imposing a moral conduct in the society) on the macroeconomic outcomes in different countries of the world (as a measure of managerial decision). The article's conclusion is that one of the efficient "law enforcement" ways is accepting religion in the social-economic space, so that the managerial decision in any corporate governance system will also have a moral component, meant to censor the immoral or antisocial decisions of managers.
\end{abstract}

Keywords: corporate governance, religion, policies enforcement, morality, ethic, social-economic space

\section{Introduction}

The apocryphal quote ascribed to Andre Malraux “The 21st century will be a religious one or it will not be at all” grinds the contemporary scientific world and finds adepts or critics in the most various areas of knowledge development. This economic crisis marked by the toxicity of derived products traded on security markets followed by the crisis of sovereign debts shows besides the end of a secular cycle in the current economic evolution - the end of the consumer society, and represents a turning point in the development of human society in general. The credibility of multinational large financial institutions' reality and seriousness of the product they are selling to the public has been deeply affected once with the great bank failures in the years 2008-2010, a fact that raised the question of improving internal control and public supervision mechanisms, with a direct impact on the corporate governance solutions adopted by these organizations.

Paul Diaconu, Professor, Faculty of Accounting, Bucharest Academy of Economic Studies.

Dan Dumitrescu, Professor, Faculty of Accounting, Bucharest Academy of Economic Studies.

Correspondence concerning this article should be addressed to Paul Diaconu, Preciziei Boulevard, No. 11, 6th District, Bucharest City, Romania. E-mail: pauldiaconu74@yahoo.com. 
The fundamental problem of corporate governance theories is that they fail to penetrate by the proposed methods the consciousness of executives, but attempt, by creating bureaucratic tools at ensuring a climate of good governance in the organization. Governance systems, either monist or dualist, recommend increasing the role of audit committees, audit parts composition, and are as many concerns that, though having improved the governance climate within organization have failed to avoid the great managerial risks and at the same time the great bankruptcies in recent years. The transition to a new stage, in the present economic thinking is required, in our opinion, one to control a larger extent the human consciousness of the decision-makers by using two basic tools also used in the past to control human consciousness: ethics and religion. Both concepts call for the need to control the cultural capital of individuals and how this can be exploited for the good of the community. If religion pertains to the embodied form of cultural capital as described in fundamental works such as "Protestant ethic and the spirit of capitalism" by Weber (Weber, 1904), ethics can be found more often in the institutionalized form of cultural capital, set by school under the condition of using the terms established by Bourdieu (1979).

In the present paper we start from the premise that the best measure of assessing corporate governance policies, viewed in the broad sense is the added value generated by companies, regardless of their size in the economy. Furthermore, we believe that the general social expectation is to maintain general welfare and to inspire a slightly trend upward increasing trend (the tendency of "blue chips” at the society's overall level). Therefore, we appraised that a statistic financial indicator which would the impact of corporate governance policies and systems is represented by the Gross Domestic Product (GDP) of the country where the various economic entities operate- the respective companies.

One of the most critical moments in social life is the moment of economic crisis. Then the developments generally accepted by society: the tendency of blue chips (slightly increasing); changes and an economic decline occurs with a significant adverse impact on the society in general (see the current economic crisis).

Starting from the premise that the measure of corporate governance policies seen in the broad sense is the respective country's GDP evolution, we intend to test the impact of religion as an instrument to impose overall welfare in the society on the corporate governance policies. We appreciate that a demonstration of this influence can be tested scientifically, by applying the general principle of cause variation and following the way in which the outcome is affected. Thus, in order to vary the religion indicator, we propose an analysis of the way in which the indicator has been affected by the outcome (GDP) in countries of a different religion (cause indicator) in the context of the current economic crisis. This is the way in which we can assess the effects of religion on the activities carried out by corporate governance actors in conditions of economic turbulence and how their overall decisions, over time, have a positive or negative consequence on the society's evolution economically, on long term.

\section{Literature Review}

Concerns about improving corporate governance mechanisms are standing in the scientific world and the new turmoil generated by the current economic crisis showed the limits of all previous conceptual constructions. However, one of the directions in which the western society has not advanced is enhancing the role of ethics and/or religion in determining a behavior of managers to the good of the shareholders community and of the general public. Important steps in raising awareness on the religion's role in managerial decision have been taken by authors of Islamic religion who emphasized in their works that the role played by Divinity in 
economic decision-making. This comes as an application of economic capital's development and exploitation in the context of recognizing the existence of a different cultural capital in the countries of a traditional Muslim religion. The role of Islam in the modern companies' system of management accounting can be found explained in works such as "Elimination of Riba through Tzakiyah (Purification) of the cash flow concept: a study from the Indonesian Islamic business habitus” presented by Mulawarman (2011) where the managerial thinking process features three phases:

First to integrate the mind and soul; second to integrate the results of the integration of mind-soul with the Owner (n.a. Allah) of the mind and soul; third, to derive the result of integration from the second level in the form of formalistic prayers as well as to read, understand, interpret and seek symbols of the Holy Qur'an to determine decision as result of integration. It is clear that business decisions are not only based on calculations of financial prediction, but the peak is on intuition and inner soul atmosphere. (p. 121)

Baydoun and Willett (2000) develop a theory about the form and the content of the financial information that should be contained in Islamic financial statements. The theory suggests that the presence of the Islamic religion as a cultural variable affects the way certain accounting measures are interpreted and the manner in which accounting information should be disclosed. Two important criteria for disclosure in Islamic accounting are identified: a form of social responsibility and the rule of full disclosure. This leads to modification of the form of the conventional western set of financial statements (ICR's). The specific recommendations are that ICR's should contain a value-added statement as the focus of performance of the accounting entry and the current value balance sheet in addition to the historic cost balance sheet. This will serve more Islamic code. The authors draw a comparison between Islamic accounting and the western conventional one in the 2000s. Thus, if western conventional accounting is underpinned by economic rationality, it is secularized, individualist, based on profit maximization and rationalism in addressing business, and concerns property as an absolute concept, Islamic accounting is based on the unity of God, with religion that masters all accounting concepts, is subject to common good, is considering a reasonable profit for the owner, is fair and regards shareholders as relative owners of the company.

Abu-Tapanjeh (2009) in "Corporate governance from the Islamic perspective: A comparative analysis with OECD principles” published in Critical Perspectives on Accounting states is a growing concern emerged with a great profile regarding the Islamic principles of corporate governance. A major ethical component of any economic activity in Islam is to provide justice, honest and fairness and to ensure all parties their rights and dues. Islamic economy has progressed a great deal during these last two decades with impetus as an important concern in developing an Islamic corporate system. Paper concluded that the dimension of Islamic perspectives of corporate governance has broader horizon and cannot compartmentalize the roles and responsibilities in which all actions and obligations fall under the jurisdiction of the divine law of Islam whereas, the OECD principles implements a firm with six different issues and obligations.

In the paper "Culture and Corporate Governance" by Aras and Crowther (2008), Riham states that culture has long been recognized as a likely determinant of business practices and ethical values (Hofstede, 1980; Gray, 1988; Perera, 1989). Traditionally religion has had a role in shaping and enforcing ethical behavior such as truthfulness, honesty, and social justice.

Hasan (2012) makes a comparison between occidental corporate governance system and Islamic corporate governance system, insisting on the role of ethics as an essential incident on corporate governance. He suggest that only after the incident of significant corporate failures and financial scandals due to lack of ethical 
consideration, there were suggestions to integrate ethics into corporate governance frameworks such Drennan (2004), Cladwell and Karri (2005), Arjoon (2005), and Sullivan and Shkolnikov (2007) cited by Hasan (2012).

In western literature, the role of religion is taken by ethics and its role in corporate governance structure or of the corporations' social responsibility policy. Thus, authors such as Epstein (1987), Verma and Prakash (2011), Griseri and Seppala (2010), Muchlinski (2008) discuss issues in business ethics and its impact on organization's welfare that should be institutionalized by the organization's culture, ethos, and operational rules. The concept of business ethics should assist companies and their leaders to incorporate value considerations and social performance issues into ongoing organizational or individual policies and practices by providing an integrative analytical framework which draws upon and fuses key elements of the older concepts of business ethics, corporate social responsibilities, and corporate social responsiveness.

Bonini, Alkan, and Salvi (2012) found in their works that corporate governance is the essential mechanism allowing proper management of financial and corporate resources by aligning incentives of employees and investors. Yet, corporate governance rules and mechanisms are costly and have different effectiveness across countries. The paper's results provide guidance to investors in selecting the appropriate set of governance provisions conditional on a set of investment-specific factors.

Nordberg (2004) in his paper seeks to reframe the discussion about corporate governance in terms of the ethical debate between consequential, teleological approaches to ethics and idealist, deontological ones, suggesting that directors are-for good reason-more inclined toward utilitarian judgments like those underpinning shareholder value. But the problems with shareholder value have become so great that a different framework is needed: strategic value, with an emphasis on long-term value creation judged from a decidedly utilitarian standpoint.

Current literature in the field of business ethics and corporate governance is extremely well represented and dwells, from various angles on the ethics role in defining corporate governance policies, insisting on the need to establish implementation and control mechanism of ethical precepts in managerial decision. Such works, as the ones of Zimmerli, Richter, and Holzinger (2007), Reinz (2007), Brink (2011) or Abdullah and Benedict (2009), Veldman (2011), Hahn (2012), Judge (2012) discuss at length the issues of ethics in corporate governance. Yet, the great advantage of the Islamic system of corporate governance, even if it is not structured as the western one, consists in the force and determination by which it succeeds in implementing Islamic precepts, close to the ethical precepts in business management.

The role of this paper is to attempt at identifying correlations between the predominant religion and its related social tools meant to impose morality in the society and at the same time generating specific social perceptions of the individuals and economic evolution of the respective countries.

\section{Hypothesis}

The predominant religion of a society leaves a mark on the respective nation's way of thinking. Depending on how the religious precepts manage to impose themselves in the society in general and particularly in economic life causes certain attitudes and a certain climate of morality and interaction with the other co-participants in the economic life. Given the philosophy of each of the four major religions: Christian, Buddhist, Hindu, and Islamic, the authors tried to identify the possible causality relations between the religion nature and the economic behavior of community's members during the last economic crisis by means of the GDP and GDP/inhabitant indicator in the period 2008-2010. The hypotheses the authors want to demonstrate 
are the following:

- There is a correlation between the evolution of GDP indicator and the religion of the respective nation;

- If Hypothesis 1 is right, which are the religions that managed better during the economic crisis the social processes, so that the decisions of the managers responsible for corporate governance do not impair the overall economic welfare of the society?

\section{Methodology}

The statistic data has been obtained based on the information provided by Google statistics and complementary from www.indexmundi.com. In the view to assessing the impact of corporate governance policies on the macroeconomic outcomes, we used the GDP indicator and GDP evolution, rectified by inflation rate. We appraised as a given fact that corporate governance policies have a direct impact on companies' economic outcomes, and the companies, by their economic outcomes, affect directly the GDP evolution (the added value generated by those being a GDP component) on the one hand, and on the other hand, the current economic crisis has caused the GDP decrease due to a lower mass of the added value generated by the companies in the respective countries, we think that the outcomes of corporate governance policies have a direct impact on GDP. We started from the different way of addressing business in various geographic areas and sought to stratify the sociological populations (nations) on religious grounds. We appraised that inspires a certain behaviour in the society, and a certain way of thinking related to social ethics, a fact that would be implicitly found also in the corporate governance policies.

We also thought that where a religion is the major (exceeds $50 \%$ of a country's population) this imposes the predominant social conduct. We considered the following religions according to which we classified the countries in the world: Christian, Buddhist, Hindu, and Islamic. A series of states had a religious mix between Buddhism, agnosticism, and Universal Chinese. We considered the respective state as being Buddhist having regard to the roots and basic philosophy of the respective religion. In order to assess the impact on the respective countries' GDP, we evaluated the GDP growth rate in constant values compared with the previous year, thus appraising the society's basic expectation: continual slightly increasing developments of this indicator.

\section{Findings}

As to Hypothesis 1:

- There is a correlation between the GDP indicator evolution and the respective nation's relation.

To test the first hypothesis we checked that the correlation coefficient is zero or different from zero.

Mathematical calculations revealed that the correlation coefficient is significantly different from zero, being equal to 0.23 .

Then we tried to classify countries, according to the GDP growth rates in the years 2008-2010 in uniform populations and then to test if possibly in thus formed growth rate classes any preponderant religion is identified for each of the formed clusters. We conducted tests for uniform populations of four clusters and after analysing the results thus obtained, we identified the fact that two of the populations were preponderantly populated with countries of a predominantly Christian religion, and the Hindus and Buddhists had significantly similar developments, which caused regrouping countries into three clusters in order to concentrate developments on the three basic directions: one significantly variable with a significant decrease of the GDP 
growth rate up to negative values; one with a slowdown of the GDP growth rate up to value close to zero, dominated by Islamic religion; and one with sustained growth rates of over $4 \%$ dominated by countries predominantly Buddhist and Hindus as it is represented in Figure 1.

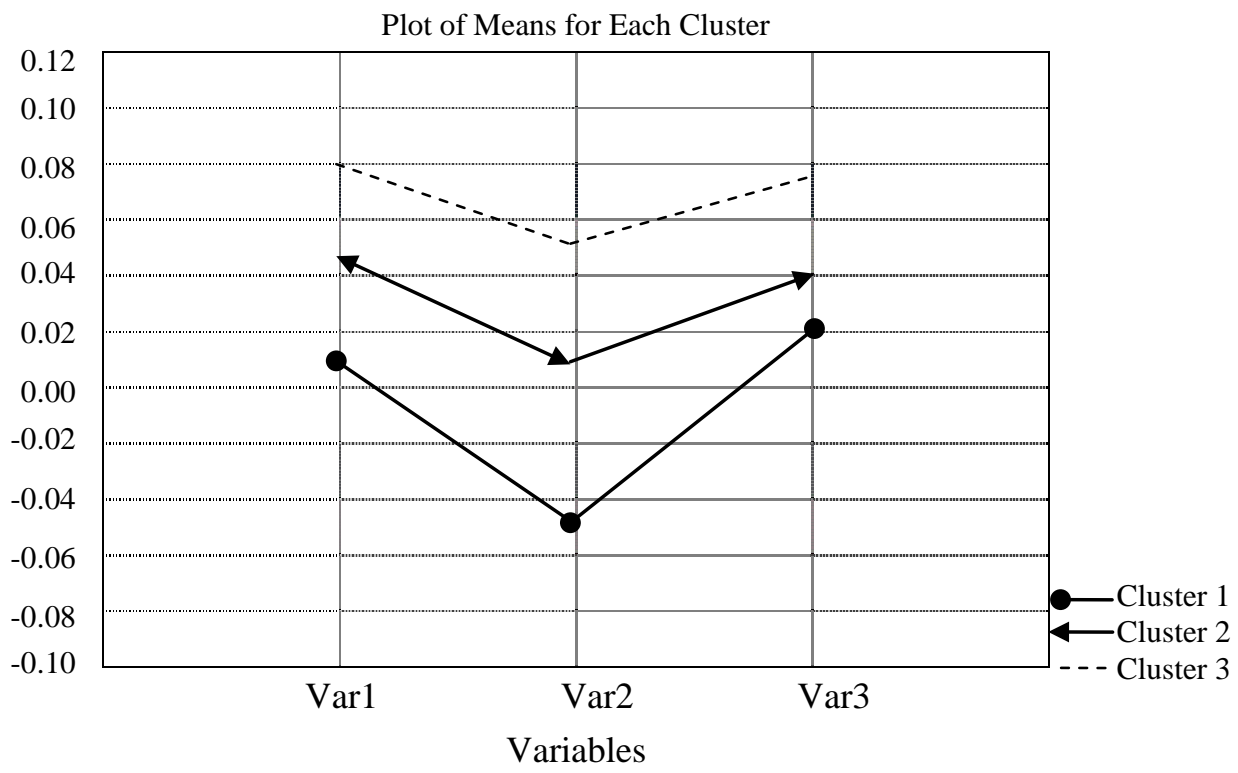

Figure 1. Plot of means for each cluster.

To test the relevance of this classification in the three categories of countries, we have used the ANOVA test that revealed the following shown in Table 1.

Table 1

Analysis of Variance

\begin{tabular}{llllrl}
\hline $\begin{array}{l}\text { Between } \\
\text { SS }\end{array}$ & $d f$ & $\begin{array}{l}\text { Within } \\
\text { SS }\end{array}$ & $d f$ & $F$ & Significance \\
& & & & $p$ \\
\hline 0.159532 & 2 & 0.195703 & 182 & 74.1810 & 0.000000 \\
0.282842 & 2 & 0.226832 & 182 & 113.4700 & 0.000000 \\
0.095094 & 2 & 0.161953 & 182 & 53.4328 & 0.000000 \\
\hline
\end{tabular}

Since the $p$ indicator value is zero, it comes out that the stratification into in three clusters is a significant one.

By correlating the results of the two mathematical determinations it comes out that Hypothesis 1 is confirmed. GDP indicator is also influenced by the major religion of the respective country and, therefore, the corporate governance policies as a tool of GDP generating and GDP development is influenced by the religion predominant in the society.

As to Hypothesis 2:

- If Hypothesis 1 is correct, which are the religions that managed better the social processes during the economic crisis so that the decisions of the managers responsible for corporate governance do not impair economic welfare of the society in general? 
A general statistical analysis related to the structure by religions of GDP and the grow rates can be concentrated in Table 2.

Table 2

A General Statistical Analysis Related to the Structure by Religions of GDP and the Grow Rates

\begin{tabular}{|c|c|c|c|}
\hline Countries & 2008 & 2009 & 2010 \\
\hline Total & $60,126.26$ & $56,913.83$ & $61,710.42$ \\
\hline Total GDP average rate \% & 1.94 & $(2.00)$ & 4.00 \\
\hline \multicolumn{4}{|l|}{ Buddhist countries } \\
\hline Total GDP value by category & $10,242.65$ & $10,868.28$ & $12,347.34$ \\
\hline GDP average rate by category $\%$ & 3.92 & 1.00 & 7.00 \\
\hline Percentage of total GDP & $17 \%$ & $19 \%$ & $20 \%$ \\
\hline \multicolumn{4}{|l|}{ Hindu countries } \\
\hline Total GDP value by category & $1,238.21$ & $1,399.06$ & $1,750.31$ \\
\hline GDP average rate by category \% & 4.95 & 9.00 & 9.00 \\
\hline Percentage of total GDP & $2 \%$ & $2 \%$ & $3 \%$ \\
\hline \multicolumn{4}{|l|}{ Islamic countries } \\
\hline Total GDP value by category & 4,182.39 & $3,804.91$ & $4,484.34$ \\
\hline GDP average rate by category \% & 4.57 & 1.00 & 5.00 \\
\hline Percentage of total GDP & $7 \%$ & $7 \%$ & $7 \%$ \\
\hline \multicolumn{4}{|l|}{ Christian countries } \\
\hline Total GDP value by category & $44,260.91$ & $40,646.19$ & $42,911.09$ \\
\hline GDP average rate by category \% & 1.13 & $(4.00)$ & 3.00 \\
\hline Percentage of total GDP & $74 \%$ & $71 \%$ & $70 \%$ \\
\hline
\end{tabular}

It is noted that the countries of Christian religion were mostly affected by the crisis, recorded in the year 2009 a decrease of the GDP rate of 4\%. Moreover, the proportion of Christian economies in the world GDP is in this period decreasing. The less affected ones, according to the statistics above, are the Buddhist and Hindu economies, followed by the Islamic ones that record lower average rates, but still positive.

We complete this general statistical classification with the mathematical statistical analysis based on clusters. This analysis by which we have grouped the world countries in three clusters depending on GDP growth rates for the years 2008-2010 has the following conclusions:

(1) Within cluster three countries with sustained GDP growth rates of over $4 \%$ in constant values are shown. The countries of a preponderantly Buddhist and Hindu religion particularly had such values, like: China, Bhutan, India, Laos, Macao, Singapore, Sri Lanka, or Vietnam. These represent $76 \%$ of total GDP of the respective cluster and $51 \%$ of total countries of Buddhist and Hindu religion. A percentage of $13 \%$ is represented by countries in the Islamic area, like: Afghanistan, Azerbaijan, Bangladesh, Cape Verde, Egypt, Gambia, Laos, Lebanon, Niger, Oman, Qatar, Sudan, Tajikistan, Turkmenistan, and Uzbekistan. They represent $31 \%$ of total GDP PIB produced by Islamic countries. The remaining $10 \%$ are representing Christian countries.

(2) The second states category, belonging to median cluster two are the ones where the growth rates were also maintained in the peak year of crisis, positive rates, they did not record negative values of GDP evolution, but only slowdowns in the growth. This group of states is predominantly Christian, 56\% of the GDP collected within the cluster, but only $11 \%$ of GDP total generated by the Christian countries. This leads to the conclusion that the predominant place of the Christian countries is not in this middle cluster, but in clusters one whose data is shown below. 
On the second place within the cluster are Islamic countries, whose GDP represents 24\% of total GDP of the respective cluster. These countries of a predominantly Islamic religion that populate cluster two are: Albania, Algeria, Saudi Arabia, Bahrain, Comoros, United Arab Emirates, Guinea, Guinea Bissau, Jordan, Iraq, Iran, Kazakhstan, Kirgizstan, Kosovo, Libya, Malaysia, Maldives, Mali, Morocco, Mauritania, Pakistan, Senegal, Sierra Leone, Syria, Tunisia, and Yemen. But they represent 50\% of total GDP of the Islamic countries, a fact that confirms the primary statistical analyses through which we reached the conclusion that these countries recorded positive developments of GDP, only recording a slight decrease of the growth rate, yet also maintained in positive values in the year 2009.

(3) The last group is represented by the one belonging to cluster one, where countries with growth rates that recorded negative values in the year 2009 are grouped. They are the countries most profoundly marked by the economic crisis and that recorded economic turmoil in full. They represent $71 \%$ of the world economy. Within this group of countries, $86 \%$ of the GDP proportion of the cluster is represented by the countries of Christian religion. Among these we mention: Austria, Bahamas, Belgium, Botswana, Bulgaria, Canada, Denmark, Switzerland, Finland, France, Germany, Greece, Ireland, Italy, Latvia, Lithuania, Luxemburg, Great Britain, Mexico, Norway, New Zeeland, the Netherlands, Portugal, Romania, Russia, Serbia, Spain, United States of America, the Ukraine, Hungary, Venezuela, and Zimbabwe. The following category of countries within the cluster is represented by the Buddhist countries with $12 \%$ of the total, represented by Japan, a country strongly dependent on the Christian western economy where it exports most of its high technology products. On the last place the Islamic countries are situated, with $2 \%$ of the proportion.

The analysis by clusters comes to demonstrate the preliminary conclusions that confirm the adverse impact of the economic crisis on Christian economies. The study continues the hierarchy by grouping the states that recorded positive growth rates, but of an average intensity up to 4\% GDP growth rate/year where the Islamic economies are major from the representation point of view, and in the last category we can find the countries with sustained growth rates, of over $4 \%$ of the cluster's average mean, where the countries of Buddhist and Hindu religion are preponderant.

\section{Conclusions}

The study has started from the need to identify new ways to impose in the organization's corporate governance structures, but also how to conduct business in general, ethical, moral precepts meant to harmonize individual with the collective welfare. Starting from the analysis of means by which, over time, the society has tried to manage the collective human behaviour, we identified besides the legislative, normative system where we situated ourselves and with the current corporate governance system, also other means meant to penetrate people's consciousness and control their actions, in order to get them act both for the individual good and for the collective one. The experience of traditionalist Islamic economies where, in the Islamic financial companies, there are the so-called groups of Islamic (religious) supervision that censor from the religious point of view the current or long term economic decisions, represents an experience worthy to be analyzed more profoundly by the secularized western capitalist society, having regard to the sequential failure generated by abuses at the corporate governance structures level of large western corporations (see the sale of toxic financial derived products on the stock exchanges around the world).

The return to religious morality, meant to control human consciousness, the only one able to make the best decisions for itself, but also for the society in general in the long term, seems to be the determined statistical 
solution that allows a better application of decisions in terms of corporate governance. In fact the only thing we are doing is to reconfirm a conclusion that the human society has cyclically reached, namely, the philosophy of goodness can only be promoted by consciousness control. Consciousness control can only be achieved through religion in general and particularly through ethics. If ethics has an action scope limited to the population cultivated on this purpose and has as single coercive tool going out of morality, religion proposes a more powerful instrument, the one of resistance in front of the divine superhuman force. Cultivating Divinity's force, generally accepted by religion as being supreme and irremovable, is done differently, its method and means customizing each individual religion.

From the study presented above, the most inefficient from this point of view comes out to be the Christian religion, exactly due to the fact that the Christian society is one preponderantly secularized. Christian religion does not have at present the means of consciousness coercion meant to ensure the promotion of common good in the society, exactly due to religion withdrawal from the society's active life in general, but especially its failure to get involved in economic life. On the other hand, Christian economy in the economic growth periods is the most dynamic by the fact that individual good is not opposed to the need to ensure community's good, only to the extent of the legislative system's observance.

From this point of view, the Buddhist and only the Hindu religion is the most efficient in promoting man's integration in the surrounding environment, determine a logic of a more harmonious existence that implicitly requires a moral conduct also in the economic life course in general and how the corporations are governed in particular. The way in which these populations conduct business starts from the premise of trust between partners and of a good balance in the exchanges between them. That is why the cognitive matrix of a manager will always be marked by the need of trust in the business partner, which requires a good balance in business and much fewer turbulences generated by this fact.

Islamic religion, given its coercive system of imposing goodness in the society manages to cause in a significant manner, a good balance in the society, which allows, during periods of economic crisis generated by lack of trust in the business partners, positive developments without notable turbulences. Islamic experience in the financial companies, represented by the committees of Islamic supervision, is a solution to the current morality crisis generated by the managerial decisions of the corporate governance structures.

We appraise that future studies will be able to test in the western society the opportunity of these committees or the implementation of other means by which management consciousness should be channeled towards the collective good, whether this is called shareholders' profit or overall social welfare.

\section{Limitations of the Study}

These are caused by the fact that, though the study analysis the impact of corporate governance policies on economic environment, taking into account the morality level existent in various societies imposed by the society's predominant religion, yet, in many states of the world, given the relatively low level of economic development, also the corporate governance policies are at an incipient developmental level, and so, how they act on economic decisions are questionable. However, we cannot deny the existence of corporate governance policies, whether they are rudimentary in each economy of the world. But this diminishes the evaluation of religion's role in imposing a moral social conduct. 


\section{References}

Abdullah, H., \& Benedict, V. (2009). Fundamental and ethics theories of corporate governance. Middle Eastern Finance and Economics, 4, 88-96.

Abu-Tapanjeh, M. A. (2009). Corporate governance from the Islamic perspective: A comparative analysis with OECD principles. Critical Perspectives on Accounting, 20(5), 556-567.

Baydoun, N., \& Willett, R. (2000). Islamic corporate reports. Abacus, 36(1), 71-90.

Bourdieu, P. (1979). La distinction: Critique sociale du jugement. Paris: Editions de Minuit.

Brink, A. (2011). Corporate governance and business ethics. Ethical Economy, 39, 95-280.

Epstein, E. M. (1987). The corporate social policy process: Beyond business ethics, corporate social responsibility, and corporate social responsiveness. California Management Review, 29(3), 99-105.

Griseri, P., \& Seppala, N. (2010). Business ethics and corporate social responsibility. United Kingdom, UK: South-Western Cengage Learning EMEA, Andover.

Hahn, R. (2012). Inclusive business, human rights and the dignity of the poor: A glance beyond economic impacts of adapted business models. Business Ethics: A European Review, 20(3), 47-63.

Hasan, Z. (2012). Corporate governance: Western and Islamic perspectives. International Review of Business Research Papers, 5(1), 277-293.

Judge, W. (2012). The importance of considering context when developing a global theory of corporate governance. Corporate Governance: An International Review, 20(2), 123-124.

Muchlinski, P. (2008). Corporate social responsibility. In P. Muchlinski, F. Ortino, \& C. Schreuer (Eds.), The Oxford Handbook of International Investment Law. Oxford: Oxford University Press.

Mulawarman, A. D. (2011). Elimination of Riba through purification (Tazkiyah) of the cash flow. Concept: A Study from the Indonesian Business Muslim Habitus, ATINER Conference in Greece.

Nordberg, D. (2004). The ethics of corporate governance. Journal of General Management, 33(4), 35-52.

Reinz, P. S. (2007). Project governance, implementing corporate governance and business ethics in nonprofit organizations, contributions to economics. New York: Physica-Verlag.

Riham, R. R. (2008). Culture and corporate governance. In G. Aras, \& D. Crowther (Eds.), Social responsibility research network. Leicester, UK.

Stefano, B., Senem, A., \& Salvi, A. (2012). The effects of venture capitalists on the governance of firms. Corporate Governance: An International Review, 20(1), 21-45.

Veldman, J. (2011). Corporate Inc.. Business Ethics-A European Review, 20(3), 292-303.

Verma, S., \& Upvan, P. (2011). Corporate governance: Business ethics and social responsibility. Retrieved from http://www.ssrn.com

Weber, M. (1904). The protestant ethic and the spirit of capitalism. In T. Parson (Ed.). New York: Charles Scribner's Sons.

Zimmerli, W. C., Richter, K., \& Holzinger, M. (2007). Corporate ethics and corporate governance. Berlin: Springer. 